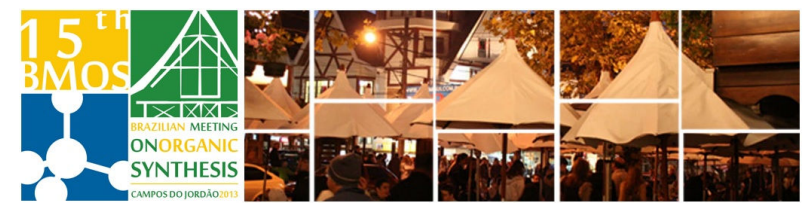

\title{
Regioselective reduction of 1-amino-2,4-dinitrobenzenes
}

\section{Cíntia de Andrade Custódio* (PG), Simon J. Garden (PQ)}

Instituto de Química, Universidade Federal do Rio de Janeiro, CT, Bloco A, Cidade Universitária - Ilha do Fundão, 21949-900 - Rio de Janeiro - RJ *cintiacustodio@ig.com.br and garden@iq.ufrj.br

Keywords: selective reduction, dinitrobenzene, stannous chloride

\section{INTRODUCTION}

The selective reduction of dinitro compounds is an important synthetic strategy for the synthesis of intermediates for dyes, pharmaceuticals and agrochemicals. ${ }^{1}$ Reduction of nitro compounds can be performed by a large number of synthetic methodologies including hydrazine with catalytic ferric chloride, ${ }^{2} \quad \mathrm{NaBH}_{4} /$ Raney nickel, ${ }^{3}$ catalytic hydrogenation, or by dissolving metals ( $\mathrm{Fe}, \mathrm{Sn}, \mathrm{Zn}$ ). However, many of these methods are not chemoselective nor regioselective for the reduction of substituted dinitro aromatics. ${ }^{4}$

The present study reports our findings with respect to the regioselective reduction of 1 -amino2,4-dinitrobenzene derivatives with $\mathrm{SnCl}_{2}$ in EtOAc. ${ }^{5}$

\section{RESULTS AND DISCUSSION}

Dinitrochlorobenzene was prepared from chlorobenzene with sulfuric and nitric acids. Nucleophilic substitution of chloride was achieved by refluxing with an amine nucleophile in ethanol. The 1-amino-2,4-dinitrobenzene derivatives were obtained in better than $90 \%$ purified yield (Figure 1).

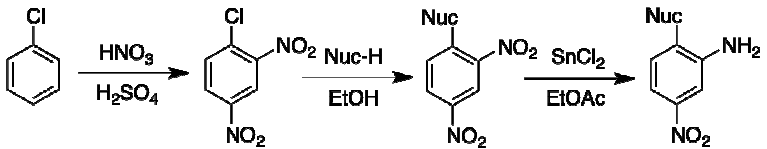

Figure 1. General Reaction Scheme

Catalytic hydrogenation $\left(\mathrm{Pd} / \mathrm{C} / \mathrm{H}_{2}\right)$ readily gave the respective triaminobenzene derivatives. A number of methods were investigated with the aim of selectively reducing one or other of the two nitro groups (for example: $\mathrm{NaS}, \mathrm{Na}_{2} \mathrm{~S}_{2} \mathrm{O}_{4}$, cat. $\mathrm{NiCl}_{2} / \mathrm{NaBH}_{4}$ ). However, we found that $\mathrm{SnCl}_{2}$ as a suspension in EtOAc gave a very highly regio- and chemo- selective mono-nitro group reduction reaction. The results varied according to the number of equivalents of $\mathrm{SnCl}_{2}$ used, the reaction time, and the nature of the amine substituent. All reactions were performed at room temperature. Some of the results are presented in Table 1. All products were characterized by ${ }^{1} \mathrm{H}$ and ${ }^{13} \mathrm{C}$ NMR spectra and GCMS analysis. The ${ }^{1} \mathrm{H}$ NMR spectra indicated reduction of the 2-nitro group as revealed by the presence of two deshielded protons ortho to the 4nitro group. The GCMS chromatogram for the reduction reaction of 1-(n-butyl)amino-2,4- dinitrobenzene with 4 equivalents of $\mathrm{SnCl}_{2}$ after 18 hours reaction time is shown in Figure 2 .

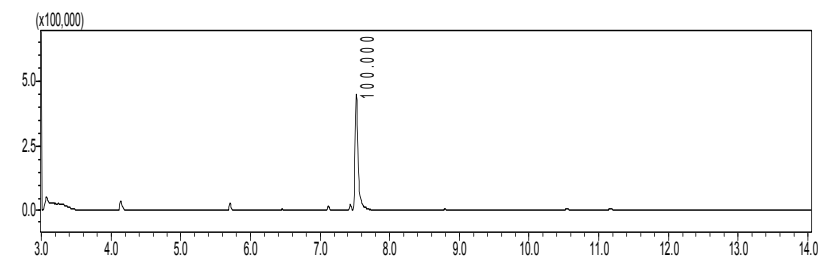

Figure 2. GCMS chromatogram 1-(n-butyl)amino-2amino-4-nitrobenzene.

Table 1. Reaction details and results for substrate reductions. Product yields are inferred from GCMS analysis of the substrate conversion.

\begin{tabular}{|c|c|c|c|c|}
\hline Nuc-H & $\begin{array}{c}\text { Mole } \\
\text { equivalents } \\
\text { of } \mathrm{SnCl}_{2}\end{array}$ & $\begin{array}{c}\text { Reaction } \\
\text { Time } \\
\text { (min) }\end{array}$ & $\begin{array}{c}\text { Mono } \\
\text { reduction } \\
\text { Product } \\
(\%)\end{array}$ & $\begin{array}{c}\mathrm{Di} \\
\text { reduction } \\
\text { Product } \\
(\%)\end{array}$ \\
\hline 5 & 4 & 30 & 70 & 18 \\
\hline \\
\hline
\end{tabular}

\section{CONCLUSION}

The use of $\mathrm{SnCl}_{2}$ as a suspension in EtOAc is a promising method for the regio- and chemoselective reduction of 1-amino-2,4-dinitrobenzenes to 1,2-diamino-4-nitrobenzenes. These products are useful intermediates in organic synthesis.

\section{ACKNOWLEDGEMENTS}

FAPERJ, CNPQ, and PGQU-IQ-UFRJ

\section{REFERENCES}

${ }^{1}$ Liu, X-Z.; Lu, S-W. J. Mol. Catal. A: Chem. 2009, 300, 36.

${ }^{2}$ a) Kislyi, K.A.; Samet, A.V.; Strelenko, Y.A. Semenov, V.V. J. Org. Chem. 2008, 73, 2285. b) Hirashima, T.; Manabe, O. Chem. Lett. 1975, 259

${ }^{3}$ Pogorelić, I.; Filipan-Litvić, M.; Merkaš, S.; et al. J. Mol. Catal. A: Chem. 2007, 274, 202.

${ }^{4}$ Noronha, R.G.; Romão, C.C.; Fernandes, A.C. J. Org. Chem. 2009, 74, 6960 .

${ }^{5}$ a) Bellamy, F.D.; Ou, K. Tetrahedron Lett. 1984, 25, 839. b)

Grig-Alexa, I.C.; Simionescu, J.; Patriciu, O.I.; Massip, S.; et al. Tetrahedron Lett. 2012, 53, 1885 